\title{
OPERATIONAL BENEFITS IN LARGE SYNCHRONOUS MACHINE WITH THE APPLICATION OF STATIC DRIVES
}

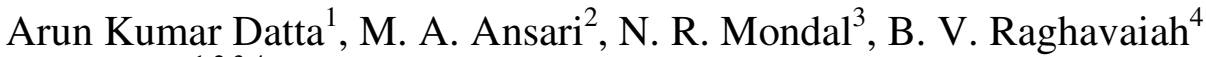 \\ ${ }^{1,2,3,4}$ Central Power Research Institute, Bhopal, India
}

\begin{abstract}
In a power plant, synchronous machine work as an alternator after coupling with a prime mover (turbine). Machine discussed in this paper is a special alternator of 1500MVA rating used to supply power in a short circuit test laboratory. This alternator was initially driven by a prime mover. It is well known that a single synchronous machine can work at a time either as a motor or as a generator. With this concept, the prime mover of the said alternator was removed to make it in dual mode operation. This is achieved with the help of three static devices; they are static frequency converter (SFC), static excitation system (SES) and power electronic controllers. This paper begins with the detailed description of SFC and SES. Thereafter it looks into the starting techniques in pulse link mode and synchronous mode. Commutation methods for thyristors under different bridges are also listed out. It has also been explained about running this large machine as motor and converting it to generator for extracting power required for electrical tests. Various modes of operation (e.g. starting, running \& stopping) and their inter changeability are also mentioned herewith. Savings in energy is the major outcome of the dual mode operation of this large machine. The energy saving techniques adopted on this machine is also part of this paper.
\end{abstract}

\section{KEYWORDS}

Synchronous generator, short circuit test, frequency converter, static excitation, pulse link mode, synchronous mode, regenerative braking.

\section{INTRODUCTION}

Starting difficulties in synchronous machine have restricted its popular use. Normally an additional device is required to facilitate the starting process. This device can be static or rotating one. Under the static device SFC technology is being used worldwide in the field of gas turbine base power plant, pump storage power plant, rail, aircraft and ship [1] - [5]. Use of SFC for a short circuit alternator is very much unique [6]. Short circuit alternator is a specially designed synchronous generator use to deliver power in electrical tests. Among these tests short circuit test is the most critical, that requires high amount of energy. As SFC gives input to the stator, rotor also requires field excitation. In earlier days conventional synchronous machines were energised with rotating exciters. During 1961 these rotating exciters were started replacing with static excitation system [7]. Short circuit alternator discussed in this paper also gets field power from static excitation system. Figure 1 depicts this alternator that was driven with a motor for ten years and presently running without motor. Its single line diagram is shown in figure 2.

\section{SYSTEM DESCRIPTION}

In the absence of driving motor the alternator has to be started as synchronous motor. Synchronous motor is not a self starting machine. It's a doubly excited machine which requires power input both in stator and rotor windings. These powers are sourced from static devices for

DOI : 10.14810/elelij.2014.3211 
this machine. Stator terminals of the alternator get supply from SFC whereas; SES energises the rotor field winding (fig.2).

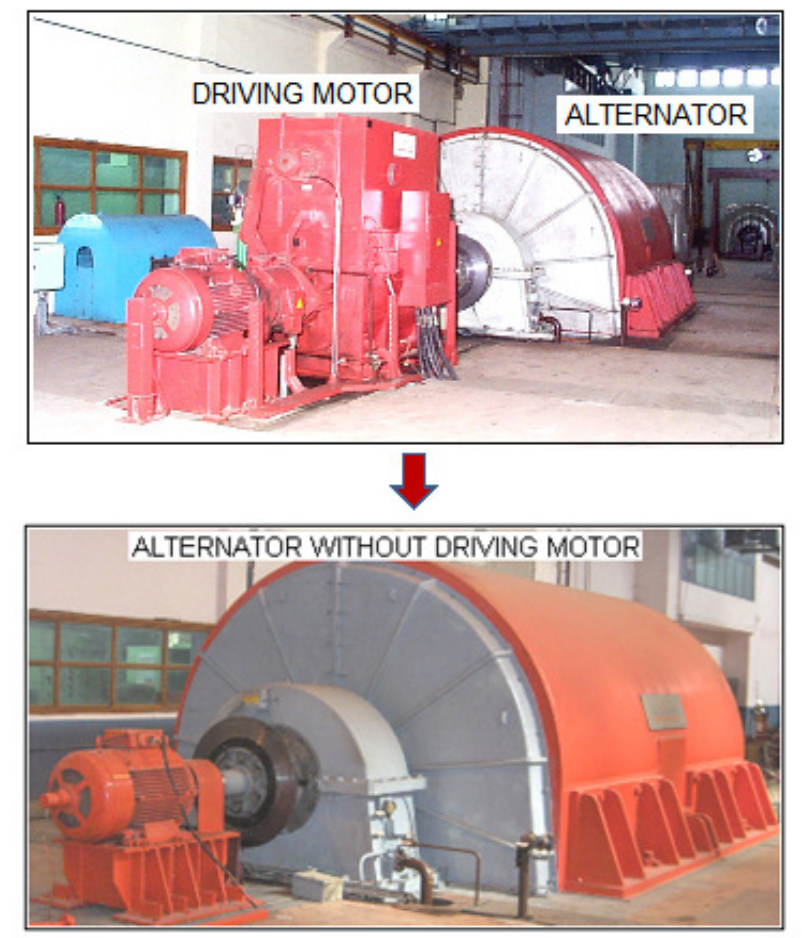

Figure 1. Short circuit alternator with \& without driving motor.

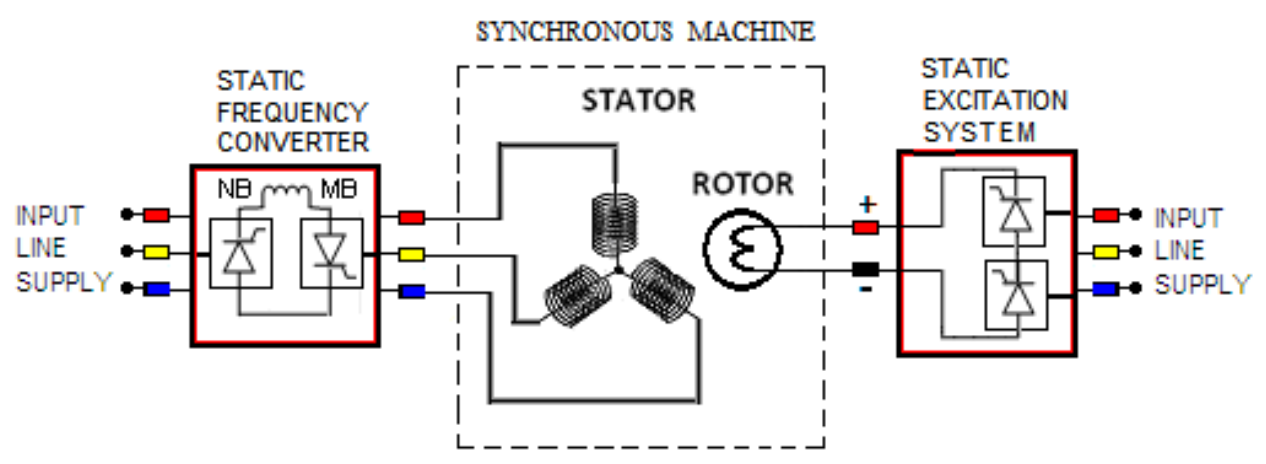

Figure 2. Static drive and excitation systems.

\subsection{STATIC FREQUENCY CONVERTER}

Frequency converters are of many types. The static frequency converter (SFC) is a combination of two 6-pulse thyristor bridges connected by a DC link (smoothing) reactor (fig. 2) and control equipment [8]. The bridge connected to the source side is called network bridge (NB). It converts line frequency supply to pulsating DC which is filtered by the smoothing reactor. This DC output is inverted to three-phase $\mathrm{AC}$ by the other bridge called machine bridge (MB). $\mathrm{MB}$ is connected to the stator terminals of the machine. The MB output frequency is varied from a very low value up to the nominal value by the SFC controller. Both these bridges can be made converter or 
inverter depending upon the machine requirements [9]. SFC control cubicle takes care of different parameters and sets the thyristor firing angle accordingly [10]-[12].

\subsection{STATIC EXCITATION SYSTEM}

To magnetise the air gap of the synchronous machine, its rotor (field) winding is excited with a dc source. This dc power is maintained here by static excitation system (SES) [13]. It is known that the power factor and harmonic components of the utility input line current can be improved by the poly-pulse AC/DC converter [14]. With this concept SES is a converter of 12-pulse configuration made from a series combination of two six pulse thyristor bridges (fig.2). A special converter transformer is used to supply power in SES. Converter transformer in SES has one primary (delta) and two secondary windings (star \& delta) with $30^{\circ}$ phase shift between them. These secondary windings feed three phase ac inputs to two separate controlled rectifiers in SES. Combined dc output from these bridges flow field current in the rotor winding and creates magnetic field. Field current is controlled by controlling the firing angle of bridge thyristors [15] with a power electronic controller (PEC). PEC acts very fast in a $\mu$ sec range during the excitation period [16].

\section{OPERATING PRINCIPLE}

\subsection{MOTOR MODE}

For the torque generation (to move the rotor) co-ordination of all the above bridges is very much important. It is explained (fig.3) in the following steps:

- $\quad$ SFC feeds the stator winding very low frequency pulses thereby activating the 'Pulse link mode'.

- Two out of three thyristor legs of machine bridge (MB) are fired which passes current through two windings at a time. This current produces stator magnetic flux $\Phi_{\mathrm{i}}$.

- Vector $\Phi_{\mathrm{i}}$ rotates in steps of 60 degrees according the sequence of the fired pairs of thyristor.

- The SES supplies current to the rotor field winding producing a magnetic flux $\Phi_{\mathrm{e}}$.

- The torque produced in the motor $\mathrm{T}_{\mathrm{m}}=\mathrm{C} \bullet \mathrm{i}_{\mathrm{d}} \bullet \cos \varphi \bullet \Psi$, where

$\mathrm{C}=$ constant, $\mathrm{i}_{\mathrm{d}}=$ average current in DC link

$\varphi=$ phase difference between current and voltage

$\Psi=$ motor flux, which is directly proportional to $\mathrm{U}_{\mathrm{m}} / \mathrm{n}$

Where, $\mathrm{Um}=$ Motor voltage, $\mathrm{n}=$ speed (revolution).

The torque reaches a maximum value when magnetic flux $\Phi_{\mathrm{e}}$ is perpendicular to flux $\Phi_{\mathrm{i}}$. It turns the rotor into direction of the acting force. After the rotor has turned by 60 degrees, the next pair of thyristor is fired (turning vector $\Phi_{\mathrm{i}}$, by 60 degrees, producing again a maximum torque on the rotor). The initial low speed (150rpm) rotation is called 'Turning Gear'. Being low back emf the natural commutation for SFC thyristors is not possible hence forced commutation is used. To get the full speed of 3000rpm MB output frequency is increased by changing the thyristor firing angle. The higher speed is called 'Synchronous mode'. Here natural commutation of thyristor is possible. The thyristor commutation steps in the bridges are given in the next paragraphs.

\subsubsection{AT LOW SPEED}

The machine does not supply enough voltage for thyristor self commutation in MB.

$>$ The NB therefore supports commutation in Pulse Mode. So each time when the current in the MB has to be commutated :

- The NB reduces the DC current to zero. 
Electrical and Electronics Engineering: An International Journal (ELELIJ) Vol 3, No 2, May 2014

- The thyristors of the inverter start to block.

- After which the new thyristor pair at the MB is fired again.

\subsubsection{AT HIGHER SPEED}

The voltage at the inverter terminal is high enough to commutate the thyristors.

$>$ The current through the newly fired thyristor increases rapidly while it reduces in the earlier fired thyristor to bring it in blocking state.
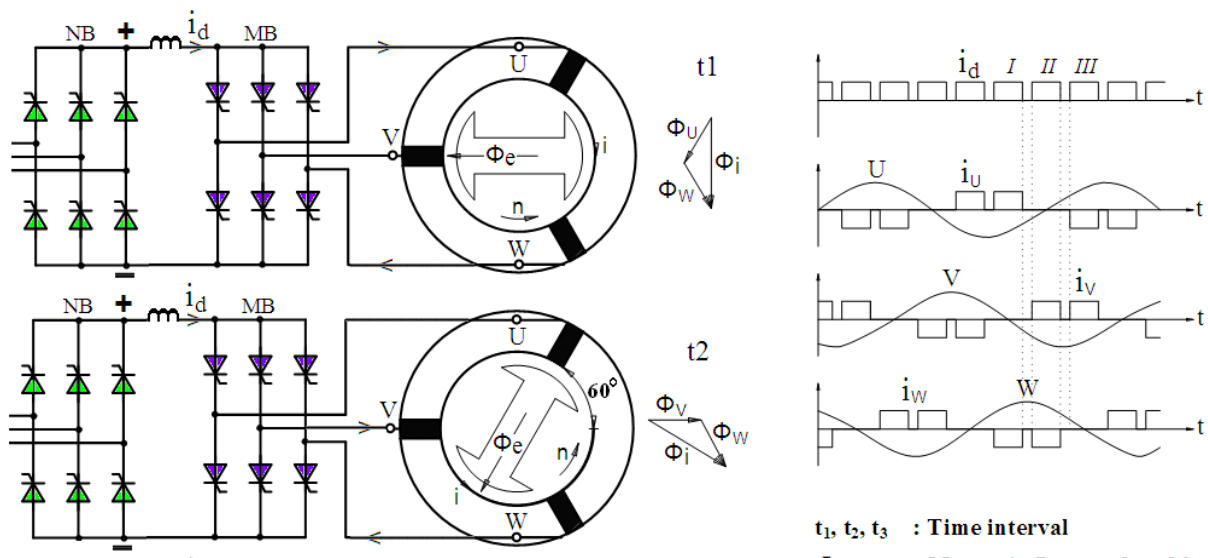

$t_{1}, t_{2}, t_{3}:$ Time interval

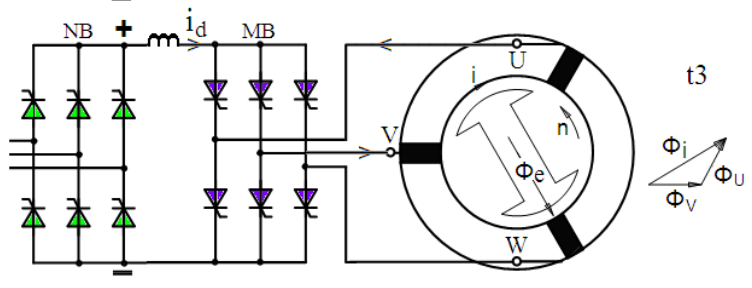

$\Phi_{\mathrm{i}} \quad$ : Magnetic flux produced by stator windings

$\Phi_{\mathrm{e}} \quad$ : Magnetic flux produced by rotor winding

: Revolution

: Stator current

: DC current

$\mathrm{m}$ : Smoothing reactor

Figure 3. SFC MB output and torque generation.

\subsubsection{AT LOW SPEED}

The machine does not supply enough voltage for thyristor self commutation in MB.

$>$ The NB therefore supports commutation in Pulse Mode. So each time when the current in the MB has to be commutated :

- The NB reduces the DC current to zero.

- The thyristors of the inverter start to block.

- After which the new thyristor pair at the MB is fired again.

\subsubsection{AT HIGHER SPEED}

$>$ The voltage at the inverter terminal is high enough to commutate the thyristors.

$>$ The current through the newly fired thyristor increases rapidly while it reduces in the earlier fired thyristor to bring it in blocking state.

\subsection{GENERATOR MODE}

Conversion of motor mode to generator is must to draw power from the machine. In this process thyristor pulses of SFC bridges are blocked to stop the power flow from the grid. Field regulation is then adjusted by the controller in the SES and the machine is changed from motor to generator 
mode. The output voltage appears at the stator terminals is equal to the set reference voltage. OCC plotted for this generator is shown in figure 4. The generator feeds the required power to the test object. One of such test results of voltage and current is depicted in figure 5. After one test cycle the machine is required to bring back to motor mode to regain its drop in speed. To implement this, SFC is made active by releasing the thyristor pulses. The motor attains full speed and is ready for the next cycle of operation. This process is repeated till the completion of all the test cycles under one category of test.

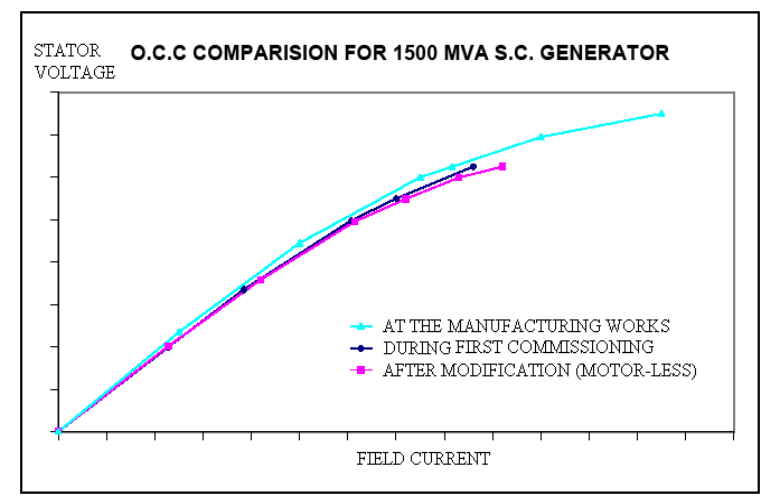

Figure 4. OCC: Stator voltage versus rotor current.

\begin{tabular}{|c|c|}
\hline $20 \mathrm{kA}$ Ir & munun \\
\hline $\begin{array}{l}20 \mathrm{kV} \\
-20 \mathrm{kV}\end{array}$ & 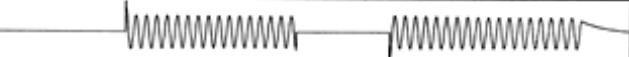 \\
\hline $\begin{array}{l}20 \mathrm{kA} \\
-20 \mathrm{kA}\end{array}$ & $-\mathrm{Mnnm} \longrightarrow \mathrm{Mnnm}$ \\
\hline $\begin{array}{l}20 \mathrm{kV} \\
-20 \mathrm{kV}\end{array}$ & 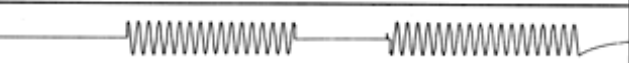 \\
\hline$\underset{-20 \mathrm{kA}}{20 \mathrm{~A} A}$ & $-\mathrm{nnnnn}$ \\
\hline $\begin{array}{l}20 \mathrm{kV} \\
-20 \mathrm{kV}\end{array}$ & HWWWOMWOWWW \\
\hline & $1200 \mathrm{~ms}$ \\
\hline
\end{tabular}

Figure 5. V \& I on test equipment (circuit breaker).

\section{ENERGY SAVING ASPECTS}

This special alternator has many edges over the conventional one. The most important is the savings in the electrical energy consumption. There are several techniques by which these savings are achieved. Some of them are briefly explained in the following paragraphs.

\subsection{ABSENCE OF DRIVING MOTOR}

Removal of $2300 \mathrm{~kW}$ driving motor from this alternator contributed the following benefits:

- Absence of windage and friction losses on motor.

- Reduced vibration and noise.

- Elimination of driving motor auxiliary systems. These are air cooling fan of $9 \mathrm{~kW}$, lubrication oil pump, water cooling pump etc.

- Cut on maintenance and expenditure involved on motor including down time of the plant. 


\subsection{MOTOR MODE}

SFC is the one of the best known static drive for starting of heavy machines. This 1500MVA alternator at motor mode draws only $94 \mathrm{Amp}$ at the starting; that too is increased very smoothly. Speed is also reached from 0 to $150 \mathrm{rpm}$. Hence the grid is not loaded at all during the starting process. This $150 \mathrm{rpm}$ rotation of the machine is called turning gear. 'Pulse link mode' is activated by the SFC for this speed. Nature of thyristor commutation is 'forced' and the machine can be kept at turning gear as long as required to stabilise the various parameters. To increase the speed, pulse link mode is changed to 'Synchronous mode' (fig.6) to get the full speed of $3000 \mathrm{rpm}$. Thyristor commutation is 'natural' at this mode and current drawn at this speed is 230 Amp. This doesn't happen during the starting of any conventional high power machine, which draws high starting current. Major part of this high starting current in other methods normally wasted in the form of heat. This is not the case for this machine.

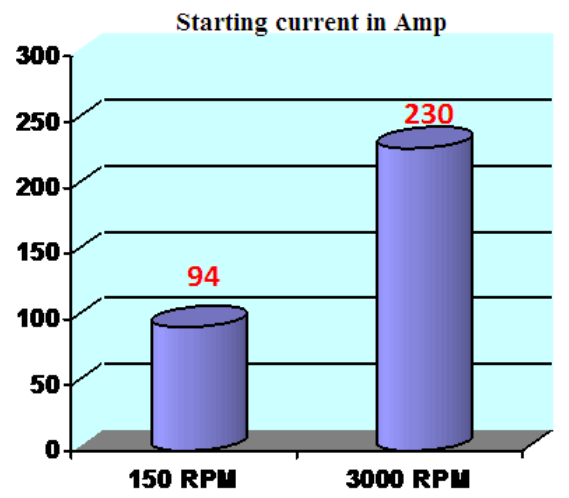

\subsection{EASY MODE CHANGE}

Figure 6. Soft starting process.

With the help of SFC the machine can be changed from 'Synchronous mode' (3000rpm) to 'Pulse link mode' (150rpm) and vice versa very easily. It is a unique feature of the SFC. Sometimes there is sufficient gap between two tests. For this idle period the machine is normally kept on reduced speed $(150 \mathrm{rpm})$ at 'Turning gear' mode. Power requirement at turning gear is only $4.5 \mathrm{~kW}$. Whereas, at full speed (i.e. at $3000 \mathrm{rpm}$ ), the machine used to draw $950 \mathrm{~kW}$ (fig.7). Other benefits of turning gear are low friction \& windage losses and reduced vibrations \& noise. Load on the auxiliary systems are also reduced at low rpm of the machine.

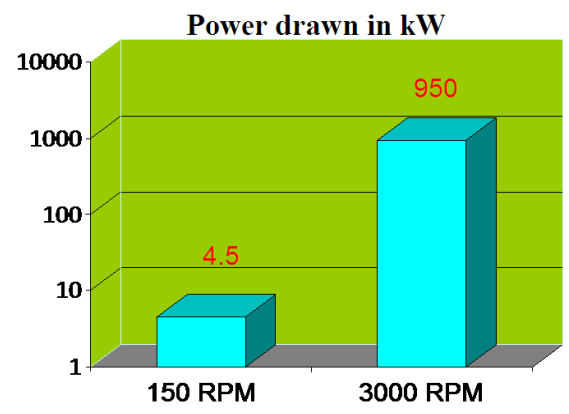

Figure 7. Comparison of power drawn. 


\subsection{UNLOADING THE GRID}

During the test cycle high amount of energy is drawn from the generator. If generator is electrically connected then that power will be drawn from the grid. To prevent this, pulses of the SFC thyristors are blocked to stop conduction of the bridges. As a backup protection a physical isolation is also given through a circuit breaker, so that there will not be any continuity with the source. The test power is drawn from the inertia only. As a result of this, a small amount of drop in the speed is observed, which is recovered again in motor mode operation.

\subsection{HIGH OPERATING POWER FACTOR}

SFC normally operates in high power factor range (0.8 to 0.9$)$. To compensate the reactive power drawn for the field excitation, power factor controller is installed, which resulted in energy saving.

\subsection{REGENERATIVE BRAKING}

Conventional stopping process of a machine under full speed involves a huge loss of energy. Other than wasting the stored energy in rotating masses some additional energy is also required to apply braking. All the energy is mostly dissipated in the form of heat. In place of conventional technique, regenerative braking is used for this machine. SFC has a great role to achieve this. It converts the machine into generator mode; $\mathrm{MB}$ acts as a converter and NB as an inverter. In this process the mechanical energy stored in the rotor under spinning is transformed into electrical energy and feeds back to the supply grid. The stopping time is also very less than the traditional methods.

\section{Conclusion}

Use of static drive for the operation of short circuit alternator is quite flexible. Practical utilization of motor-generator reversible theory has been implemented nicely with the SFC technology. It is very much interesting that a big machine of 1500MVA capacity can be started softly drawing only 94 Amps (initial value) from the supply source. The state of art technology eases the monitoring, control and fault diagnosis of the system. The absence of driving motor gives us savings on energy, maintenance and down time of the generator. Operating power factor is also the highest among this type of machines. Speed of the machine can be set according to the need. Technology up-gradation has major impact on energy conservation aspects. The plant is now run with lesser units of energy. Environmental issues are also taken by using the regenerative braking. Otherwise the braking process emits a lot heat in the atmosphere. Vibration, noise level, frictional and windage losses are also minimized in this new system. With many great features the system is operating absolutely trouble free and this technology can be extended to other applications also.

\section{REFERENCES}

[1] Tian-Hua Liu, Chih-Ying Lin, Jin-Shyr Yang, Wen-Yao Chang, "Modeling and performance of a static frequency converter starting a 300 MVA synchronous machine", pp. 45-53, Volume 37, Issue 1, April 1996, Electric Power System Research, Elsevier.

[2] Shin-Hyun Park, Seon-Hwan Hwang, Jang-Mok Kim, Ho-Seon Ryu, Joo-Hyun Lee, “A Starting-up control algorithm of large synchronous generation motor for Gas Turbosets", IEEE International Symposium on Industrial Electronics ISIE, pp.502-508, 2008. 
[3] Zhang Yu-zhi, "Study of process of starting pumped storage machines by static frequency converter with field current controlled", IEEE International Conference on Signal Processing Systems, pp. V1$224-\mathrm{V} 1-227,2010$.

[4] A. Hisanori Taguchi, et al., "APS Control Method for Gas Turbine Startup by SFC”, International Power Electronics Conference, pp.264-269 IEEE, 2010.

[5] Robert B., Fisher, P.E., "Introduction of Static Frequency Converters on SEPTA's 25Hz Commuter Rail System”, pp.149-155, IEEE.

[6] Datta A. K., Manisha Dubey, N. R. Mondal, B. V. Raghavaiah, "Motor-less operation of Short Circuit generator - A CPRI Perspective", International Conference on Electrical Power and Energy Systems (ICEPES-2010), pp.439-445, 26-28 August 2010 MANIT, Bhopal.

[7] L. J. Lane, D. F. Rogers, P. A. Vance, "Design and Tests of a Static Excitation System for Industrial and Utility Steam Turbine-Generators”, pp.1077-1085, A.I.E.E., 1962.

[8] Tore Peterson, Kjell Frank, "Starting of large synchronous motor using static frequency converter", paper 71 TP 519-PWR for IEEE International Symposium on High Power Testing, Portland, Ore., pp.172-179, July 18-23, 1971.

[9] Datta Arun Kumar, Dubey Manisha, Jain Shailendra, "Study of Shaft Voltage on Short Circuit Alternator with Static Frequency Converter”, pp.692-698, Vol:7 No:11, 2013, International Journal of Electrical, Electronic Science and Engineering, World Academy of Science, Engineering and Technology.

[10] Tian Hua Liu, et al.,"Modeling and Harmonic Elimination for a Static Frequency Converter Driving a 300 MVA Synchronous Machine”, pp.602-607, IEEE, 1996.

[11] Ho-Seon Ryu, et al "A Study of Synchronous Motor Drive using Static Frequency Converter" EPEPEMC, pp.1496-1499, 2006, IEEE.

[12] Datta Arun Kumar, Ansari M. A., Mondal N. R., Raghavaiah B. V. "A Novel Use of Power Electronics: Prime Mover-less Alternator with Static Drive \& Excitation System" International Journal of Electronics \& Communication Technology, Vol. 3, Issue 1, pp. 472-475, January - March 2012.

[13] R.C. Schaefer, "Applying Static Excitation Systems", pp. 41-49, IEEE Industry Application Magazine Nov/Dec1998.

[14] Tsorng-Juu Liang, et al, “Analysis of 12 Pulse Phase Control AC/DC Converter”, IEEE 1999 International Conference on Power Electronics and Drive Systems, PEDS'99, pp.779-783, July 1999, Hong Kong.

[15] Datta Arun Kumar, Dubey Manisha, Jain Shailendra, "Investigation of Bearing Currents in Dual Mode Operation of Synchronous Machine with Static Excitation System”, pp.45-53, Vol. 2, No. 4, November 2013, Electrical and Electronics Engineering: An International Journal (ELELIJ), Wireilla Scientific Publications, Australia.

[16] Datta A. K., G. Venkateswarlu, M. A. Ansari, N. R. Mondal, "Excitation Control during Short Circuit Test Sequence of 1500 MVA Short Circuit Generator", International Conference on Advances in Computer, Electronics \& Electrical Engineering (ICACEEE-2012), pp.207-211, 25-27 March 2012 Mumbai.

\section{AUTHORS}

Arun Kumar Datta graduated in Electrical Engineering in 1990 from Govt. Engineering College, Bilaspur in India. In 1992 he did his post graduation (M.Tech.) from MACT (REC), Bhopal, India. In March 1993 he joined Central Power Research Institute (CPRI) India and looking after the Operation \& Maintenance of two 1500MVA short circuit generator plant and $33 \mathrm{kV}$ substation at Bhopal unit. He is also the Deputy Quality Assurance Co-ordinator of CPRI Bhopal unit. He had undergone training at the works of M/s. Alsthom, France. He is a Certified Energy Auditor from Bureau of Energy Efficiency (BEE) and also a member of Institution of Engineers India). He has attended many International \& National Conferences and has many papers on his credential. Other than his regular assignments he is also pursuing Ph.D. from Maulana Azad National Institute of Technology (MANIT), Bhopal. 
M. A. Ansari has obtained B.E. Electrical Engineering from Govt. Engg. College Bilaspur in 1984. Joined CPRI in Oct 1984. Worked for 10 years in 100MVA Online Testing Station and carried out testing of various LT equipments \& transformers as per IS/IEC. Since 1995 working in 1500 MVA short circuit testing station as Operation and Maintenance Engineer. He is also Quality Assurance Co-ordinator of CPR,I STDS Bhopal laboratories.

N. R. Mondal graduated in Electrical Engineering from Maulana Azad College of Technology, Bhopal in 1982. He obtained M. Tech degree from MACT Bhopal in 1992. From 1982 to 1984 he worked for NHPC in the field of commissioning of projects. In 1984 he joined CPRI. At present working as Joint Director (O\&M) and looking after overall Operation and Maintenance of 1500 MVA Short Circuit Test Station.

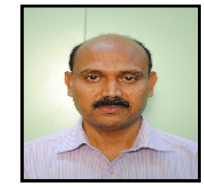

B. V. Raghavaiah has post graduated in 1981 with specialization in Power Systems \& High Voltage Engineering from JNTU, Hyderabad, joined Central Power Research Institute, Bhopal as Scientist in 1981. He is associated with testing and certification of all LT/HT electrical and other allied transmission and distribution equipments and implemented various developmental projects, R\&D works, consultancy works and also involved in third party inspections in India and abroad. He has presented several

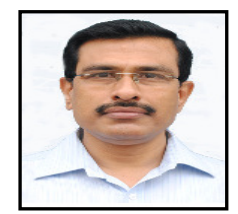
technical papers in National and International levels. Presently he is holding the position of Additional Director and Unit Head of CPRI, Bhopal. He is a member of BIS, CIGRE, and many other regulatory bodies and organisations constituted by GOI. He visited ABB Switzerland, CESI Italy test laboratories, represented CPRI at Malaysia for preparation and finalisation of transformer specifications for Global bids for TNB, Malaysia. He has also visited Japan to witness the tests as international inspector of Short Circuit testing Liaison (STL). 